
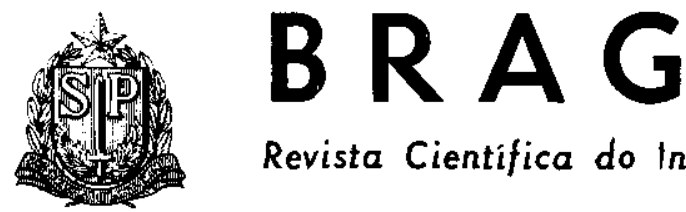

A
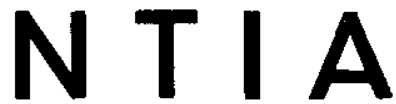

Revista Cientifica do Instituto Agronômico, Campinas

Vol. 41

Campinas, dezembro de 1982

Artigo n. ${ }^{\circ} 19$

\title{
EFEITO DE DOSES DE BORO APLICADAS NO SULCO DE PLANTIO DO ALGODOEIRO, EM SOLO DEFICIENTE (')
}

Nelson Machado da Silva (2), Luiz Henrique Carvalho, Ederaldo José Chiavegato, Seção de Algodão, Nelson Paulieri Sabino(2), Seção de Tecnologia de Fibras, e RÚter HIRoce (2), Seçāo de Química Analítica, Instituto Agronômico.

\section{RESUMO}

Em um Latassolo Vermelho-Amarelo - fase arenosa, deficiente em boro para a lavoura algodoeira, no municipio de Leme (SP), foram conduzidos ensaios de campo com doses variáveis do micronutriente durante os anos agrícolas de 1976/77, 1977/78 e $1978 / 79$. No primeiro ano, o boro foi fornecido no sulco de plantio nas doses de $0,0,0,5$,

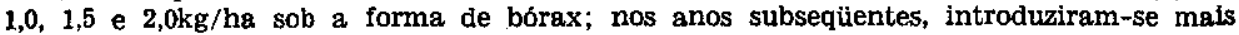
dois níveis: 0,75 e $1,25 \mathrm{~kg} / \mathrm{ha}$. A adubaçāo básica anual foi $10-60-75 \mathrm{~kg} / \mathrm{ha}$ de $\mathrm{N}, \mathrm{P}_{2} \mathrm{O}_{5}$ e $\mathrm{K}_{2} \mathrm{O}$, no sulco de plantio, e duas coberturas de $30 \mathrm{~kg} / \mathrm{ha}$ de $\mathrm{N}$. $O$ efeito médio do boro sobre a produção de algodáo em caroço foi positivo e altamente significativo, com tendência para crescer com o nível de produtividade das plantas. Estudo econômico, segundo método do trinómio do segundo grau, revelou a dose de $1,23 \mathrm{~kg} / \mathrm{ha}$ de $\mathrm{B}$ como a mais econômica, com receita líquida da ordem de $\mathrm{Cr} \$ 22.862,00$ por hectare, devida à aplicação do micronutriente. O peso médio de um capulho e a precocidade de colheita também foram influenciados favoravelmente, enquanto a maturidade da fibra se mostrou prejudicada pela adubaçáo boratada. Dentre os sintomas relatados como de deficiencia do micronutriente, destacaram-se: deformaçőes na flor, atraso no ciclo das plantas, engrossamento e rachaduras no caule, superbrotamento e anéts concêntricos no pecíolo e no caule.

\section{INTRODUÇÃO}

A retirada do $B(2 \mathrm{~kg} / \mathrm{ha}) \mathrm{da}$ mistura de adubos minerais, em dois ensaios conduzidos em solos de campo cerrado de São Paulo, em meados de 1960, fez cair abruptamente a produtividade do algodoeiro (10); em outros três experimentos, a inclusão de B ( $2 \mathrm{~kg} / \mathrm{ha})$ e $\mathrm{Zn}(3 \mathrm{~kg} / \mathrm{ha})$, associados, na adubação mineral, proporcionou aumentos sensíveis na produção das plantas (11). Infelizmente, estudos dos efeitos isolados

(1) Trabalho apresentado no XVIII Congresso da Sociedade Brasileira de Ciência đo Solo, realizado em Salvador (BA), no período de 30 de agosto a 4 de setembro de 1981. Recebido para publicação a 7 de dezembro de 1981 .

(2) Com bolsa de suplementaçăo do CNPq. 
de micronutrientes não deram seqüência a esse trabalho inicial, de modo que até meados de 1970 inexistiam normas de recomendação de elementos menores para a cultura algodoeira em nosso meio (7). Trabalhos desenvolvidos em outros países até essa ocasião, referiam-se a algumas vantagens do uso do boro na adubação, em determinadas situações. Aumentos de produtividade variando de 45 a $1.396 \mathrm{~kg} / \mathrm{ha}$ de algodão em caroço, foram registrados com o uso de doses variáveis de $B$ (de 0,5 até $1,7 \mathrm{~kg} / \mathrm{ha}$ ), enquanto várias anomalias eram relatadas como sintomas de deficiência do micronutriente $(4,6,8,12,15,16)$.

Com a ocupação de áreas de solos planos e de baixa fertilidade observada nas últimas décadas em regiões paulistas tradicionalmente algodoeiras, os sintomas de carência de boro têm sido observados com mais freqüência (5). Estudo preliminar conduzido em casa de vegetação (17), utilizando solo arenoso presumivelmente deficiente no micronutriente, permitiu caracterizar os sintomas de carência e de toxicidade, e fornecer indicações para futuros ensaios em condições de campo, iniciados em 1976. No presente trabalho, são apresentados e discutidos resultados de três experimentos visando determinar a resposta do algodoeiro à adubação com boro, no mesmo solo carente que serviu de base para o estudo inicial em casa de vegetação.

\section{MATERIAL E METODOS}

No município de Leme (SP), em solo de campo cerrado, classificado como Latossolo Vermelho-Ama- relo - fase arenosa, de acordo com - Serviço Nacional de Pesquisas Agronômicas (2), cultivado com o algodoeiro mediante aplicações sucessivas de calcário e de adubações minerais, foram iniciados vários projetos visando estudar a adubação boratada do algodoeiro. Resultados de um ensaio permanente de calagem $\mathrm{x}$ boro foram apresentados, parcialmente, em trabalho anterior (3). Próximo a esse experimento, conduziram-se nos anos agrícolas de 1976/ $77,1977 / 78$ e $1978 / 79$ ensaios visando determinar a curva de resposta do algodoeiro à aplicação de boro, no sulco de plantio. As análises químicas (dados médios) e físicas de amostras de solo revelaram os resultados constantes do quadro 1 .

No primeiro ano, o boro foi fornecido na adubação de plantio nas doses de $0,0,5,1,0,1,5$ e $2,0 \mathrm{~kg} / \mathrm{ha}$. Nos anos subseqüentes, introduziram-se mais dois níveis: 0,75 e $1,25 \mathrm{~kg} / \mathrm{ha}$. Adotou-se esquema em quadrado latino e o produto comercial utilizado foi bórax (11\% de B). N, $\mathrm{P}_{2} \mathrm{O}_{5}$ e $\mathrm{K}_{2} \mathrm{O}$ foram aplicados no sulco de plantio, a cada ano, nas doses de 10 , 60 e $75 \mathrm{~kg} / \mathrm{ha}$ respectivamente, com o uso de sulfato de amônio, superfosfato triplo e cloreto de potássio. Duas coberturas com sulfato de amônio, cedendo $30 \mathrm{~kg} / \mathrm{ha}$ de $\mathrm{N}$ por vez, foram efetuadas, uma após o desbaste e, outra, no início do florescimento das plantas. $O$ plantio foi realizado com a variedade 'IAC 17', no espaçamento de $0,75 \mathrm{~m}$ entre linhas, tendo-se deixado após a raleação cerca de sete plantas por metro linear. As parcelas experimentais foram constituídas de quatro linhas de $5,0 \mathrm{~m}$ de comprimento, sendo as duas 
centrais consideradas úteis para a coleta de dados.

A colheita do algodão foi efetuada em duas etapas. Antes da primeira, coletaram-se amostras de capulhos para estudos de laboratório, quais sejam: determinações do peso médio de capulho e de sementes, porcentagem de fibra, comprimento, resistência e índices de finura e maturidade da fibra algodoeira. Dividindo-se o peso obtido na primeira colheita pelo peso total de algodão em caroço, obteve-se a precocidade da colheita, expressa percentualmente. Ainda com os dados de produção, foi efetuado estudo econômico da adubação boratada. Nos dois últimos anos, colheram-se folhas do algodoeiro para análises químicas do limbo, segundo normas indicadas em estudo anterior (9), submetendo-as, também, à determinação de boro (1).

Com respeito à produção, são apresentados resultados das análises estatísticas dos dados por ensaio e da análise conjunta segundo esquema proposto por PIMENTEL GOMES (13). Para as demais características, visando a simplificação, são apresentados e discutidos os resultados médios dos três anos.

O estudo econômico da adubação boratada foi efetuado com dados médios dos três anos, segundo método do trinômio do segundo grau, dada a natureza sempre quadrática de reação do algodoeiro à adubação. Desse modo, utilizou-se a equação:

$$
\hat{y}=a+b x+c x^{2}
$$

onde:

$$
\begin{aligned}
\hat{y}= & \text { receita líquida esperada } \\
& \text { devida à aplicação de } \\
& \text { boro; } \\
\mathbf{x}= & \text { dose de boro usada. }
\end{aligned}
$$

A receita bruta foi obtida multiplicando-se a produção média pelo

\begin{tabular}{|c|c|c|c|c|c|c|}
\hline MO & $\mathrm{pH}$ & $\mathrm{Al}^{:+}$ & $\mathrm{Ca}^{2+}$ & $\mathrm{Mg}^{2+}$ & $\mathbf{K}$ & $\mathbf{P}$ \\
\hline$\%$ & $\ldots$ & - & $100 \mathrm{ml}$ & $\ldots$ & $-m$ & $A-$ \\
\hline 1,8 & 5,9 & - & 1,6 & 0,7 & 41 & 9 \\
\hline
\end{tabular}
valor médio do algodão, pago aos

\begin{tabular}{|c|c|c|c|c|}
\hline \multicolumn{2}{|c|}{ Areia } & \multirow{2}{*}{$\begin{array}{c}\text { Total } \\
\text { de } \\
\text { areia }\end{array}$} & \multirow{2}{*}{ Argila } & \multirow{2}{*}{ Limo } \\
\hline Grossa & Fina & & & \\
\hline 46,7 & 36,5 & 83,2 & 15,4 & 1,2 \\
\hline
\end{tabular}
produtores de março a julho de cada ano, de acordo com dados

QUADRO 1 - Análises químicas e físicas das amostras de solo (1)

(1) Agradecimentos săo devidos ao Dr. Nicanor Carvalho, pela cessão da área experimental, à Seçăo de Fertilidade do Solo do Instituto Agronómico, pela análise química, e ao Dr. Guido Ranzani, pela análise física. 
Vol. 41, Art. n. ${ }^{\circ} 19$

obtidos junto ao Instituto de Economia Agrícola (14), ou seja, de Cr $\$ 8,31$ por quilograma de algodão em caroço. No cálculo da receita líquida, foram abatidos, da receita bruta, o preço médio do adubo de Cr $\$ 136,67 / \mathrm{kg}$ de $\mathrm{B}$ (levantado junto ao lavrador), juros de $12 \%$ ao ano sobre o capital empregado e o preço médio da colheita do acréscimo de produção, de $\mathrm{Cr} \$ 1,83 / \mathrm{kg}$ de algodão em caroço (14).

Durante o desenvolvimento das plantas, foram efetuados levantamentos visando detectar sintomas de deficiência e de toxicidade de boro. feito um breve relato sobre $o$ as- sunto e apresentadas fotos de alguns sintomas de carência.

\section{RESULTADOS E DISCUSSĀO}

\subsection{Efeitos sobre a produção e análise econômica}

No quadro 2, são apresentadas as médias de produção de algodão em caroço obtidas por tratamento em cada um dos ensaios de campo conduzidos no período $1976 / 77$. $-1978 / 79$. São apresentadas, também, as médias calculadas para os três anos agrícolas e resultados das análises de variância, individuais e conjunta.

QUADRO 2 - Resultados de análises de variância e de produtividade de algodäo, obtidos anualmente nos ensaios de adubaçäo boratada no sulco de plantio do algodoeiro, cultivado em Latossolo Vermelho-Amarelo - fase arenosa, no periodo 1976/77-1978/79, em Leme (SP)

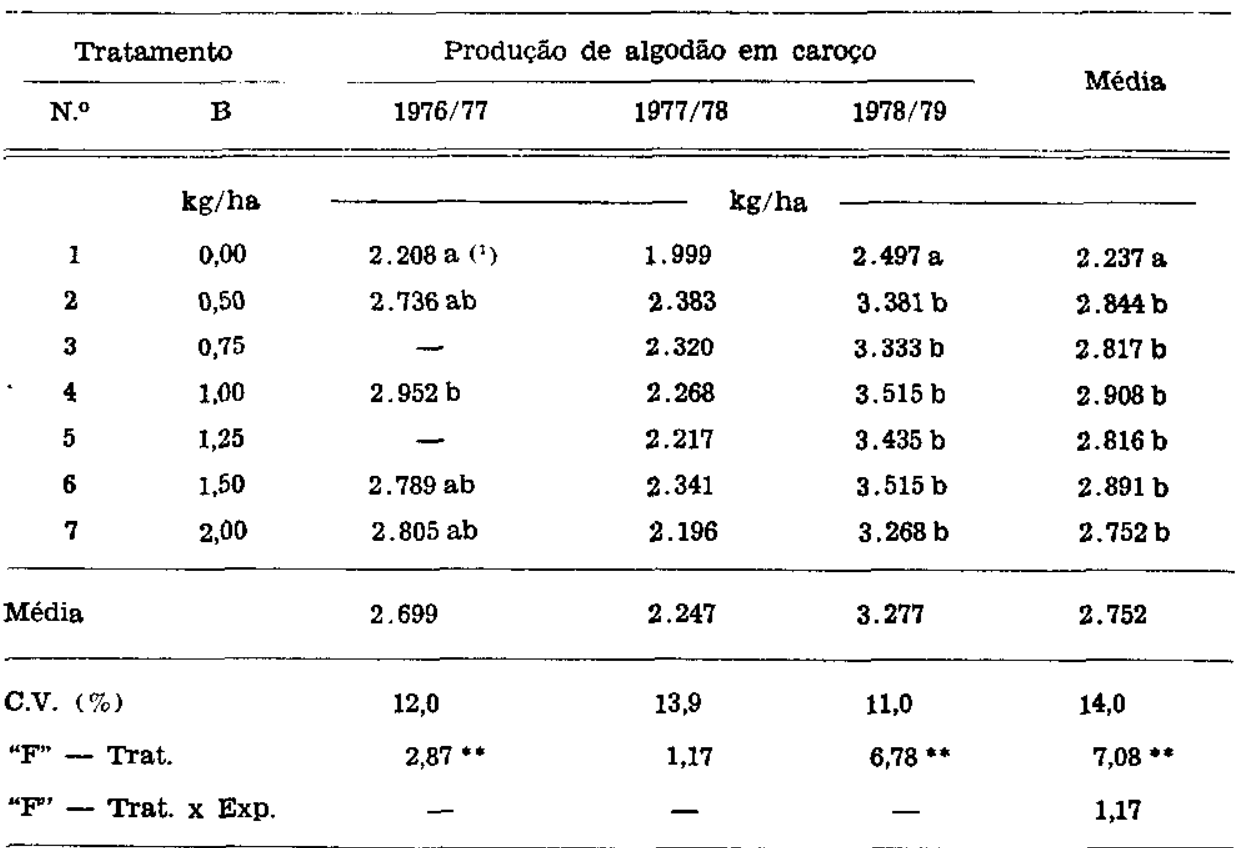

(1) Teste de Tukey, a $5 \%$. 
Em linhas gerais, o efeito médio do boro acompanhou o nível de produtividade das plantas que, representado pelo tratamento testemunha (n. $\left.{ }^{\circ} 1\right)$, cresceu na seguinte ordem: $1.999 \mathrm{~kg} / \mathrm{ha}$ de algodão em çaroço, em $1977 / 78 ; 2.208 \mathrm{~kg} / \mathrm{ha}$, em $1976 /$ 77 e $2.497 \mathrm{~kg} / \mathrm{ha}$, em 1978/79. Ora, considerando apenas os tratamentos comuns aos três anos $(1,2,4,6$ e 7$)$, nota-se que os acréscimos médios de produção devidos à adubação boratada foram, respectivamente, $298 \mathrm{~kg} /$ /ha $(15 \%), 613 \mathrm{~kg} / \mathrm{ha}(28 \%)$ e $923 \mathrm{~kg} / \mathrm{ha}(37 \%)$. Assim, pode-se admitir que em condições favoráveis para boa formação de carga no algodoeiro, deve crescer a necessidade das plantas em boro.

Ainda no quadro 1 , observa-se que no tratamento testemunha $\left(\mathrm{n}^{\circ}{ }^{\circ}\right.$ 1), foram obtidas as menores produções, em qualquer dos anos de estudo, e que expressivos aumentos foram alcançados com o uso de boro, como o de $1.018 \mathrm{~kg} / \mathrm{ha}$ (tratamentos n. ${ }^{\circ} 4$ e 6), em 1978/79, índice este comparável aos melhores efeitos até então relatados em trabalhos congêneres $(\mathbf{3}, \mathbf{8})$.

Embora os resultados discutidos demonstrem a importância da aplicação do boro na cultura do algodoeiro em solo deficiente, nota-se nesse quadro que a produção das plantas aumentou até os níveis intermediários de adubação, com tendência para diminuir após isso, mesmo no ano de menor efeito $(1977 / 78)$. Em consequuência, a ação do micronutriente acabou sendo de natureza quadrática, nos três anos, razão por que se adotou como modelo, para o estudo econômico, o trinômio do segundo grau. Na figura 1 é apresentada a curva de resposta do algodoeiro à adubação boratada, em termos de receita líquida relativa.

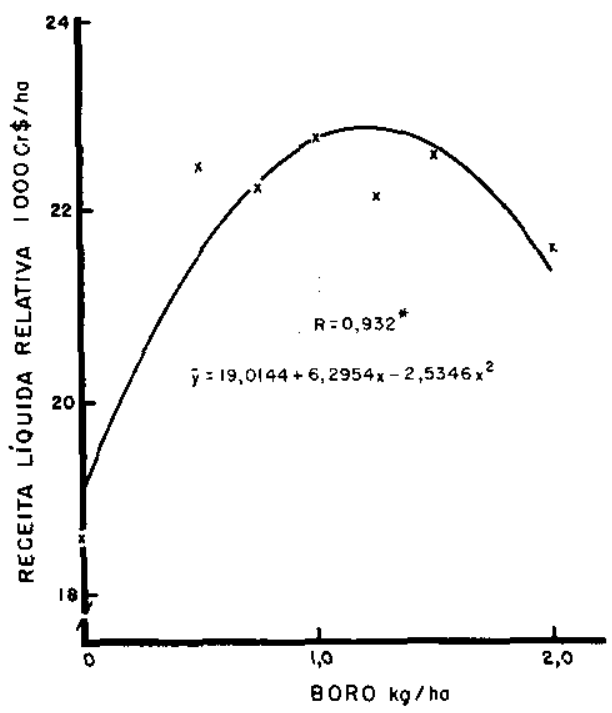

Figura 1. - Representação gráfica da equação de regressazo curvilinea, entre receita liquida telativa (y) , calculada em funçz̃o da produs 20 média de algodāo em caroso, obtida no período $1976 / 77$ - 1978/79, e doses de boro $(\mathrm{X})$, cedidas por ocasižo do plantio.

Convém ressaltar que no estudo de regressão linear obteve-se valor não significativo para o coeficiente de correlação $(r=0,582)$. Já no estudo de regressão curvilínea, de segundo grau, o coeficiente foi bem maior, tendo alcançado significância estatística $(R=0,932 *)$. A dose de boro considerada mais econômica, nesse caso, foi $1,23 \mathrm{~kg} / \mathrm{ha}$ com um retorno da ordem de $\mathrm{Cr} \$ 22.862,00$ por hectare. Esses resultados se mostram muito próximos aos obtidos em estudo anterior, no mesmo tipo de solo (3). 
No quadro 3, são apresentados os resultados médios obtidos no estudo de certas características da planta que se mostraram influenciadas pela adubação boratada, a saber: precocidade de colheita, concentração de boro no limbo foliar, peso de capulho e maturidade da fibra algodoeira.

Embora na análise conjunta dos dados de precocidade da colheita não se tenha alcançado significância estatística para o efeito de tratamento, decidiu-se pela apresentação e análise dos resultados por duas razões: houve tendência para aumento do volume relativo da primeira colheita do algodão com a aplicação de boro $(8 \%$ em média), mais ou menos constante nos três anos de estudo; ademais, obteve-se correlação significativa $\left(R=0,894^{*}\right)$ no estudo de regressão curvilínea, entre os dados médios de produção em $\mathrm{kg} / \mathrm{ha}(\hat{\mathrm{y}})$ e de precocidade (\%) da colheita (X) $\hat{y}=-87842,3+2517,9797 \mathrm{X}-$ - 17,4724X $\mathrm{X}^{2}$, com máxima produção esperada de $\hat{y}=2875,3 \mathrm{~kg} / \mathrm{ha}$, para precocidade de $\mathrm{X}=72,1 \%$ ).

No caso da concentração de boro no limbo foliar, os resultados do quadro 3 referem-se à análise conjunta dos dois últimos anos de estudo, uma vez que em 1976/77 não foi coletada amostra de folhas. Embora - valor do teste " $F$ " para tratamentos tenha alcançado significância estatística, ocorreu interação muito grande entre tratamentos e experimentos $(\mathrm{F}=3,95 * *)$. Dessa forma, fez-se necessária uma análise individual dos dados por ano agrícola. Em 1978/79, as médias dos tra-

QUADRO 3 - Resultados médios de precocidade (peso da primeira colheita x 100/peso da colheita total), concentraçăo de boro no limbo foliar, peso de um capulho e maturidade da fibra, obtidos na análise conjunta dos ensaios de adubação boratada, conduzidos com o algodoeiro no período 1976/77-1978/79, em Leme (SP)

\begin{tabular}{|c|c|c|c|c|c|}
\hline \multicolumn{2}{|c|}{ Tratamento } & \multirow{2}{*}{$\begin{array}{c}\text { Precocidade } \\
\text { de } \\
\text { colheita }\end{array}$} & \multirow{2}{*}{$\begin{array}{l}\text { B no } \\
\text { limbo } \\
\text { foliar }\end{array}$} & \multirow{2}{*}{$\begin{array}{l}\text { Peso de } \\
\text { um } \\
\text { capulho }\end{array}$} & \multirow{2}{*}{$\begin{array}{c}\text { Maturidade } \\
\text { da } \\
\text { fibra }\end{array}$} \\
\hline N.o & B & & & & \\
\hline & $\mathrm{kg} / \mathrm{ha}$ & $\%$ & $\mathrm{ppm}$ & $\mathrm{g}$ & $\mathrm{g}$ \\
\hline 1 & 0,00 & 66,4 & 30,4 & $6,44 a\left(^{(1)}\right.$ & $54,367 b\left({ }^{1}\right)$ \\
\hline 2 & 0,50 & 72,1 & 35,0 & $6,66 \mathrm{ab}$ & $52,672 \mathrm{ab}$ \\
\hline 3 & 0,75 & 72,7 & 33,9 & $6,52 \mathrm{ab}$ & $52,016 \mathrm{ab}$ \\
\hline 4 & 1,00 & 71,2 & 35,8 & $6,86 \mathrm{~b}$ & $52,636 \mathrm{ab}$ \\
\hline 5 & 1,25 & 74,0 & 34,9 & $6,55 \mathrm{ab}$ & $49,940 \mathrm{a}$ \\
\hline 6 & 1,50 & 69,1 & 36,4 & $6,55 \mathrm{ab}$ & $51,045 \mathrm{ab}$ \\
\hline 7 & 2,00 & 70,1 & 39,1 & $6,63 \mathrm{ab}$ & $51,505 \mathrm{ab}$ \\
\hline Média & & 70,8 & 35,1 & 6,60 & 52,026 \\
\hline C.V. $\%$ & & 12,1 & 16,2 & 5,4 & 8,0 \\
\hline "F" - & & 1,73 & $3,09^{*}$ & $2,72 *$ & 1,91 \\
\hline "F" - & ( Exp.) & 0,59 & $3,95^{* *}$ & 1,53 & 0,58 \\
\hline
\end{tabular}

(1) Teste de Tukey, a $5 \%$. 
tamentos $1,2,3,4,5,6$ e 7 foram, respectivamente, 40,$7 ; 39,7 ; 40,7$; 40,$3 ; 40,3 ; 39,0$ e 40,1 , não tendo havido efeito da adubação. Já em $1977 / 78$ as médias foram, em ordem: 20,$0 ; 30,3 ; 27,0 ; 31,3 ; 29,6$; 33,9 e 38,1 , sendo que, pelo teste de Tukey, a 5\% (d.m.s. de 10,0), alguns tratamentos adubados (n. ${ }^{\circ} \mathrm{s} 2,4,6 \mathrm{e}$ 7) diferiram da testemunha (tratamento n. $\left.{ }^{\circ} 1\right)$. Nesse ano, a concentração do micronutriente variou de 14 a 28 ppm de B, no tratamento testemunha, dados semelhantes aos obtidos em condições de casa de vegetação (10 a $38 \mathrm{ppm}$ de B), quando se usou o mesmo tipo de solo (17), e que se aproximam muito de resultados obtidos em solos de cerrado (14 a 48 ppm de B), em condições de campo (11). No entanto, como o fato não se repetiu no ano subsequiente, justamente quando o efeito do boro sobre a produtividade do algodoeiro foi mais sensível, não se pode tomar como definitivos tais resultados. Convém que se dê continuidade ao estudo de análise foliar de boro, visando à confirmação para os resultados até agora obtidos.

o peso médio de um capulho, por sua vez, aumentou com a adubação boratada até o nivel de $1,0 \mathrm{~kg} /$ /ha de B (tratamento n. ${ }^{\circ}$ 4). Em trabalhos anteriores, é feita referência a resultados semelhantes $(3,4)$. A maturidade da fibra algodoeira, por outro lado, caiu com a aplicação de boro, a ponto do valor obtido para um dado tratamento $(1,25 \mathrm{~kg} / \mathrm{ha}$ de B), diferir estatisticamente da testemunha. Como tais tratamentos correspondem, respectivamente, ao mais precoce e ao mais tardio, pode-se admitir que a razão da diferença observada esteja ligada ao ciclo das plan- tas. Uma hipótese seria que as plantas das parcelas testemunhas, sendo mais tardias, teriam disposto de mais tempo para elaboração da fibra, o que, associado ao menor número de capulhos por planta, poderia resultar em fibras mais maduras.

\subsection{Sintomas de deficiência de boro}

Principalmente nos pecíolos foliares das parcelas testemunhas, observaram-se anéis concêntricos de coloração escura, com engrossamento do tecido, pilosidade mais intensa $\mathrm{e}$ necrose interna da medula. Observou-se, ainda, que "ponteiros" cloróticos, com folhas novas enrugadas, pecíolos curtos e às vezes contorcidos, faziam contraste nítido com a parte inferior das plantas ("baixeiro"), mais verde e com folhas bem desenvolvidas. Sintomas semelhantes foram descritos em trabalhos anteriores $(\mathbf{3}, \mathbf{5}$, $6,8,12,15,16,17$ ).

Certas anomalias da flor do algodoeiro, a exemplo de outros estu$\operatorname{dos}(3,5,6,8,15,17)$, foram atribuídas à quantidade inadequada de boro na adubação. Nos canteiros testemunhas ou pouco adubados, com maior frequiência, foram encontradas corolas atrofiadas, com bordos das pétalas virados para dentro, resultando em abertura deficiente da flor (figura 2); muitas dessas pétalas apresentavam manchas escuras na parte interna e fino crestamento nos bordos; os estames tinham comprimento irregular, os grãos de pólen, coloração amarelada intensa $e$, $o$ estigma, formato anormal. As brácteas eram mais amareladas que as normais $\mathrm{e}$ chegavam a envolver totalmente a corola, no caso de atrofia desta (figura 3 ). Os frutos, menores que os 


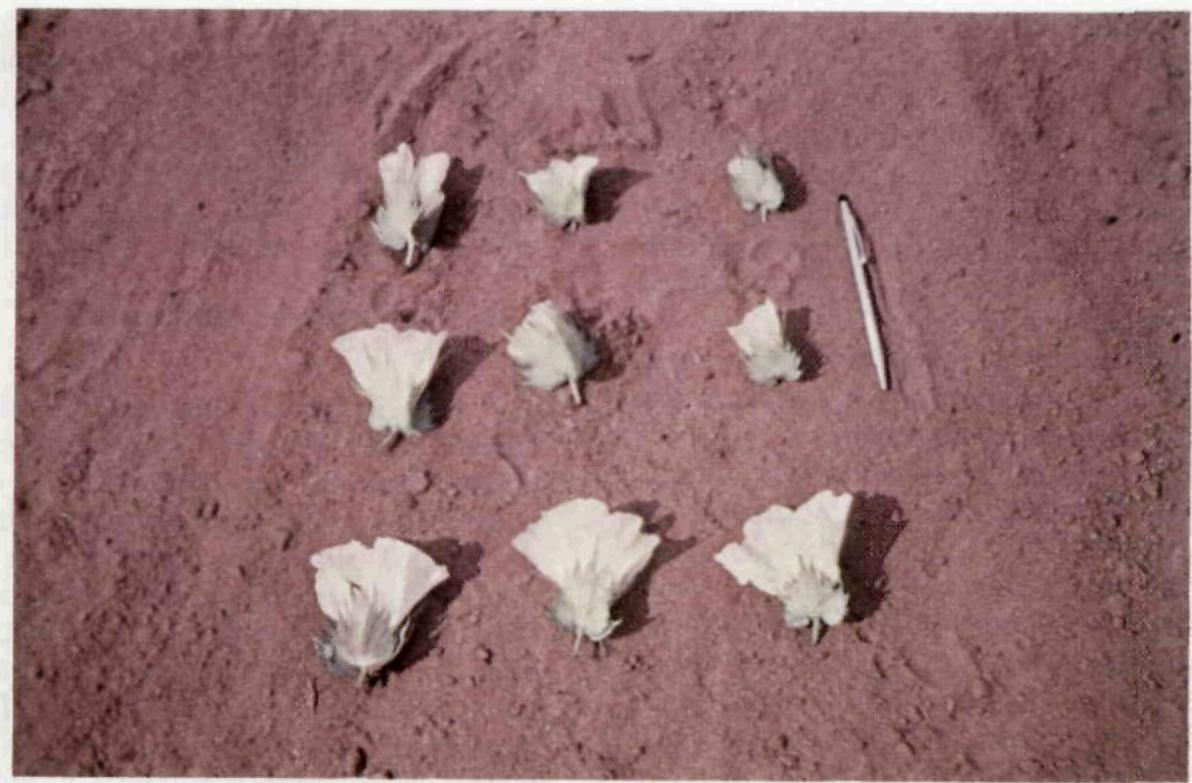

Figura 3. - Sintoma de deficiência de boro: brácteas envolvendo quase totalmente as corolas de flores colhidas em parcelas sem boro (acima), em contraste com flores normais de parcelas adubadas (abaixo).

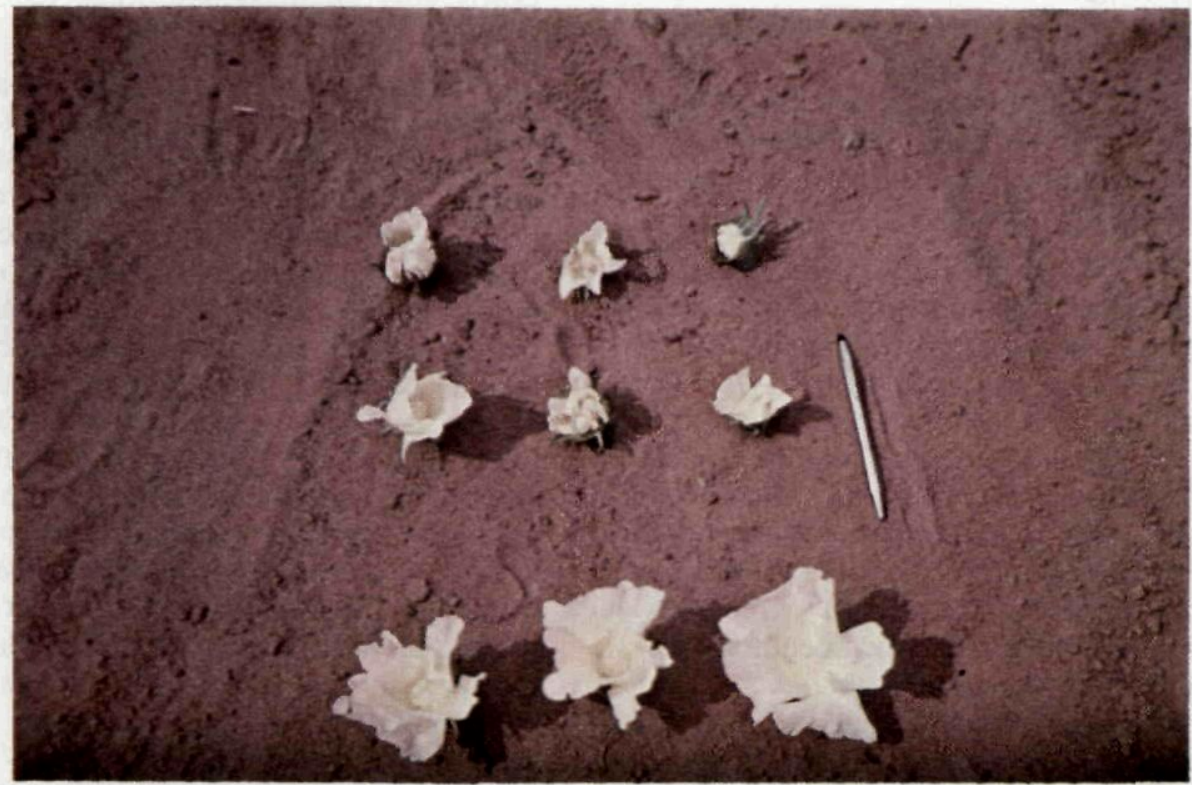

Figura 2. - Sintoma de deficiência de boro: flores com corolas atrofiadas, freqüentes nas parcelas sem boro (acima), em contraste com flores normais de parcelas adubadas (abaixo). 
normais, apresentavam necrose interna na sua base; muitos se mumificaram no "baixeiro" das plantas. A queda de flores e frutos novos, nessa situação, foi excessiva. A 3 de janeiro de 1979, ou seja, no ano de mais acentuada deficiência, procedeu-se a uma contagem de flores defeituosas no ensaio. As médias percentuais de flores anormais obtidas para os tratamentos fornecedores de 0,$0 ; 0,5$; 0,$75 ; 1,0 ; 1,25 ; 1,5$ e $2,0 \mathrm{~kg} / \mathrm{ha}$ de $B$, foram respectivamente 38,4 ; 11,$4 ; \quad 7,3 ; 4,1 ; 2,5 ; 3,7$ e 0,0 , tendo-se observado alta correlaçẫo curvilínea $\left(\mathrm{R}=0,971^{* *}\right)$ entre os referidos dados.

Nas parcelas testemunhas, ainda, o algodoeiro apresentou um ciclo vegetativo mais longo, maior desenvolvimento e pouca carga. Houve engrossamento do nó no caule principal, rachaduras na base de alguns nós, superbrotamento no ápice das plantas, com o aparecimento de internódios irregulares e, às vezes, anéis concêntricos no próprio caule, com necrose respectiva da medula interna (figura 4). Sintomas semelhantes foram descritos em outros trabalhos $(3,5,8,11,15,16,17)$.

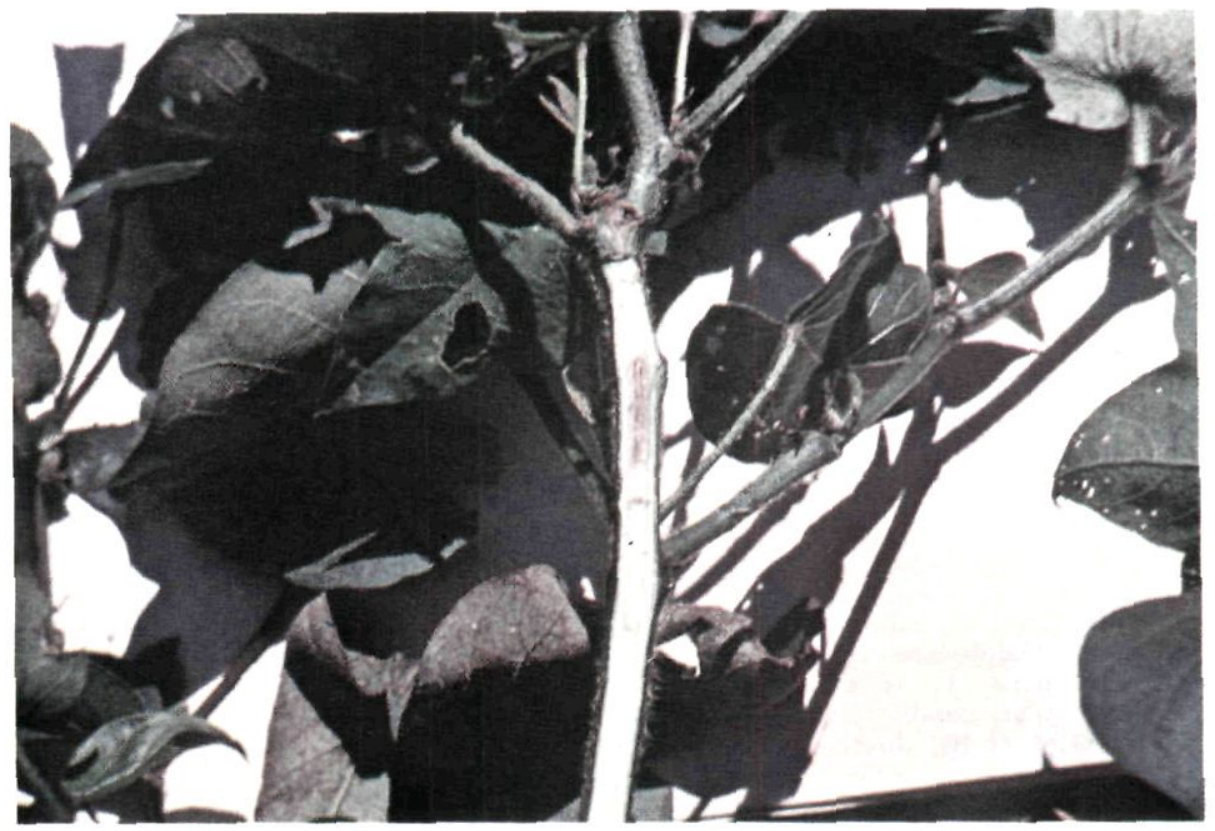

Figura 4. - Sintomas de deficiencia de boro: engrossamento do nó no caule principal, rachadura na base de alguns nós. superbrotamento e necrose interna da medula do caule de planta sem adubação boratada. 


\section{CONCLUSOES}

Do exposto no presente trabalho, podem ser ressaltados os seguintes aspectos:

a) $\mathrm{Na}$ tentativa de recuperar solo ácido e de baixa fertilidade, do tipo Latossolo Vermelho-Amarelo fase arenosa, com o uso de calcário e de adubações anuais com macronutrientes, pode-se estar criando condições para o estabelecimento de problemas nutricionais com boro na cultura algodoeira;

b) Aplicando-se, nessa situação, boro no sulco de plantio, foi obtido efeito positivo e significativo sobre a produção e observada uma tendência para esse efeito crescer proporcionalmente ao nível de produtividade das plantas; c) Admitindo-se uma correlação curvilínea entre as doses de boro utilizadas $e$ as receitas líquidas por área, devidas à aplicação do micronutriente, e considerando os valores médios do preço do bórax e do algodão em caroço, foi calculada a dose de $1,23 \mathrm{~kg} / \mathrm{ha}$ de $\mathrm{B}$ como a mais econômica;

d) A aplicação de boro aumentou, também de forma quadrática, o peso médio de um capulho e a precocidade da colheita; por outro lado, a maturidade da fibra mostrou-se prejudicada pela adubação boratada;

e) Sintomas de deficiência de boro foram observados principalmente nas parcelas testemunhas, com destaque para deformações na flor, atraso no ciclo das plantas, engrossamento e rachaduras no caule e superbrotamento e anéis concêntricos no pecíolo e no caule.

\section{COTTON RESPONSES TO BORON APPLICATION AT PLANTING TIME IN A DEFICIENT SOIL}

\section{SUMMARY}

The effect of boron application on cotton at planting time was studied in a deficient red-yellow latosol sandy phase soil, located at Leme, State of São Paulo, Brazil. Field experiments were conducted during three years namely 1976/77, 1977/78 and 1978/79. In the first year, boron was applied at the levels of $0,0.5,1.0,1.5$ and $2.0 \mathrm{~kg} / \mathrm{ha}$ of $\mathrm{B}$, as borax $(11 \%$ of $B)$. In the subsequent years, levels of 0.75 and $1.25 \mathrm{~kg} / \mathrm{ha}$ of $B$ were introduced in the experimental area. A latin square design was used in all the trials.

A positive effect on cotton yield resulted from boron fertilization. The response to boron was greater at a higher level of plant productivity. With regards to economical aspects, the optimum rate of boron was $1.23 \mathrm{~kg} /$ ha of $B$. The influence of micronutrient on earliness and weight of bolls was statistically significant and of a quadratic form, also. Otherwise, boron decreased fiber maturity.

Plants of check plots showed severe boron deficiency symptoms such as abnormalities of flowers, dark rings and pith necrosis in leaf petioles and in stems, and plant with longer vegetative cycle, excessively branched, with enlarged, dark and ruptured nodes. 


\section{REFERÊNCIAS BIBLIOGRAFICAS}

1. Bataglia, O. C.; TEIXeIRA, J. P. F.; FURLANI, P. R.; FURLANI, A. M. C.; GALLO, J. R. Métodos de análise quimica de plantas. Campinas, Instituto Agronômico, 1978. 31p. (Circular, 87)

2. BRASIL. Serviço Nacional de Pesquisas Agronômicas. Comissāo de Solos. Levantamento de reconhecimento dos solos do Estado de São Paulo. Rio de Janeiro, Ministério da Agricultura, 1960. 634p. (Boletim, 12)

3. CARVAlHO, L. H. Efeitos da calagem e da adubação boratada sobre o algodoeiro (G. hirsutum, L.) cultivado em Latossolo Vermelho Amarelo - fase arenosa. Piracicaba, Escola Superior de Agricultura "Luiz de Queiroz", 1980. 64f. (Tese de Mestrado)

4. COLEMAN, R. Wield and quality of cotton can be improved by boron. Better Crops, New York, 21(4):18-20; 48-50, 1945.

5. COSTA, A. S.; CARvalho, N.; GALlO, J. R.; COSTA, D. S. Deficiência de boro, anomalia do algodoeiro em São Paulo que se assemelha a uma virose. Fitopatologia, Lima, 11(1):10-11, 1976.

6. FRITZ, A. La déficience en bore du cotonnier au Nord-Cameroun. Coton et Fibres tropicales, 26(2):235-241, 1971.

7. FUZATTO, M. G. Adubação mineral. In: CULTURA e adubação do algodoeiro. Săo Paulo, Inst. Bras. de Potassa, 1966. p.475-508.

8. HINKLE, D. A. \& BROWN, A. L. Secondary nutrients and micronutrients. In: ADVANCES in production and utilization of quality cotton - principles and practices. Ames, Iowa Sta. Univ. Press, 1968. p.280-366.

9. HIROCE, R.; SILVA, N. M.; NAGAI, V.; BATAGLIA, O. C.; GALLO, J. R. Diagnose da nutrição nitrogenada e potássica do algodoeiro (G. hirsutum 'IAC 13-1') pela análise química foliar. Ciência e Cultura, São Paulo, 28(1):51-56, 1976.

10. MCClUNG, A. C.; FREITAS, L. M. M.; MIKKELSEN, D. S.; LOTT, W. L. A adubaçāo do algodoeiro em solos de campo cerrado no Estado de São Paulo. Instituto de Pesquisas IRI, 1961. 35p. (Boletim, 27)

11. MIKKELSEN, D. S.; FREITAS, L. M. M.; McCLUNG, A. C. Efeitos da calagem e adubação na produção de algodāo, milho e soja em três solos de campo cerrado. Instituto de Pesquisas IRI, 1963. 48p. (Boletim, 29)

12. MILEY, W. N.; HARDY, G. H.; STURGIS, M. B.; SEDBERRY JR., J. E. Influence of boron, nitrogen and potassium on yield, nutrient uptake and abnormalities of cotton. Agronomy Journal, 61:9-13, 1969.

13. PIMENTEL GOMES, F. Curso de estatística experimental. 4, ed. Piracicaba, Escola Superior de Agricultura "Luiz de Queiroz", 1970. 430p.

14. PROGNOSTICO. Săo Paulo, Instituto de Economia Agrícola, 1977/78, 1978/79 e $1979 / 80$.

15. ROTHWELL, A.; BRYDEN, J. W.: KNIGHT, H.; COXE, B. J. Boron deficiency of cotton in Zambia. Cotton Growing Review, 44:23-28, 1967.

16. SEDBERRY JR., J. E.; NUGENT, A. L.; BRUPBACHER, R. H.; HOLDER, J. B.; PHILlIPS, S. A.; MARSHALL, J. G.; SLOANA, L. W.; MELVILLE, D. R.; RABB, J. L. Boron investigations with cotton in Louisiana. Baton Rouge, Louisiana Agric. Exp. Sta., 1969. 27p. (Bulletin, 635)

17. Silva, N. M.; CARVAlHo, L. H.; BATAGlia, O. C.; HirOCE, R. Efeitos do boro em algodoeiro cultivado em condiçōes de casa de vegetação. Bragantia. Campinas, 38:153-164, 1979. 